\title{
The Emerging Knowledge Governance Approach within Open Innovation: Its Antecedent Factors and Interior Mechanism
}

\author{
Hongli Wang \\ Department of Business Administration, Tongji University \\ Tongji University Science \& Technology Park \\ NO.67, Chifeng Road, Shanghai 200092, China \\ E-mail: lovelywxuan@126.com \\ Zhenglong Peng \\ Department of Business Administration, Tongji University \\ Tongji University Science \& Technology Park \\ NO.67, Chifeng Road, Shanghai 200092, China \\ E-mail: pzlong@sh163.net \\ Feng Gu \\ Department of Business Administration, Tongji University \\ NO.67, Chifeng Road, Shanghai 200092, China \\ E-mail: lovelywxuan@hotmail.com
}

Received: January 19, 2011 Accepted: February 25, 2011 doi:10.5539/ijbm.v6n8p94

Sponsoring information: National Chinese Social Fund (10BGL033); National Chinese Nature Fund (71002019/G0213)

\begin{abstract}
The "knowledge governance approach" is characterized as an emerging approach that cuts across the fields of knowledge management within open innovation and adjusts mutual behavior that parties taking participate in open innovation to be expected. The paper proposed that knowledge governance approach is positively related to open innovation, and then the research has explored the antecedent factors and working mechanism of knowledge governance within open innovation based on Grounded Theory. By way of literature analysis and qualitative research (deeply discussion numbered 27), the paper has derived four dimension of knowledge governance (knowledge property, knowledge activity parties, the exogenous and endogenous context of knowledge activity) and the categories of each dimension. The paper has considered that the knowledge governance is formed by the interplay between interactive value creation process at the knowledge property-level and cooperation unity achieving process at the knowledge activity parties-level. We develop two theoretical models, while one is for explaining the antecedent factors of knowledge governance within open innovation, the other is for explaining the mediating role of knowledge governance in the relationship between knowledge property and knowledge activity parties level antecedents. The paper has strengthened the function of quantitative research, and will be helpful in open innovation theory and practice.
\end{abstract}

Keywords: Open innovation, Knowledge governance, Grounded theory

\section{Introduction: the emerging knowledge governance requirement within open innovation}

As firms implementing open innovation at an increasing rate (Khanna et.al, 1998), it becomes more important to understand how these firms can be instrumental in organizing and governaning the various knowledge process and undesirable behaviors that take place in open innovation. In the request to better understand the dynamics of open innovation, many researchers has relied on transaction cost economics, organizational learning, resource-based view, social exchange theory and agency theory, etc. Common for such researches, however, very little attention has been directed to understanding how exactly firms may differ in their motive to succeed at collaborating innovation. Very little is known about the individual behavior level preconditions of successful knowledge exchange in open innovation. In this paper we argue that how valuable knowledge is successfully shared and opportunism is avoided, the specific focus must be devoted to the role of knowledge governance, proposed by Foss (2006), to examine how knowledge transactions which differ in their characteristics and 
governance mechanisms which differ with respect to how it handles transactional problems are matched for behavior adjusting and reshaping. That is to say, the critical reason underlying open innovation is no longer knowledge management problems, referring to gather scattered knowledge and improve the knowledge flow. But the threat of perceiving needs to satisfy the verfying innovation parties coming from different groups and the opportunity for the globally extending innovative resources to be utilized. Under such situation, governance shows its more advantages than management. Governance can make a "bridge" between the individual micro behavior and organization macro emergence through effective mechanism design, and displays a profound insight in micro.

In this article, we propose that (1) knowledge governance approach is of significance to knowledge movement within open innovation, and (2) antecedents of knowledge governance are either knowledge property or knowledge activity parties in nature. Our main contention is that some of the core mechanisms fostering successful open innovation may be interactive value creation held by knowledge property factors, while other incentives of achieving unity may be knowledge activity parties' hold.

It is worth noting that the minority of knowledge governance is employing quantitative methods for its difficult in collecting data. A major goal of this paper based on Grounded Theory wants to contribute to mining and refining Knowledge Governance dimensions and its antecedent factors under open innovation for its later empirical study. Yet before we turn to the analysis of how the antecedents of Knowledge Governance approach we outline key characteristics that is at stake - why the knowledge governance approach within open innovation. Knowledge governance would affect and reshape the motivation of knowledge activity parties, even their behavior by designing some kind of organizational forms or institutions today or in the future.

\section{Why the knowledge governance approach within open innovation}

\subsection{Knowledge governance}

Social-Tech has opened up a new perspective of organization studies, and transformed the research focus from organization structure to human behavior involving in organization. As a kind of unique emerging method, Knowledge Governance is just the reflection of this idea. The strategy field has witnessed a proliferation of approaches that place knowledge governance center stage (e.g., Grant, 1996; Spender, 1996; Kogut and Zander, 1996). Knowledge governance stands out as a distinctive part in knowledge management for its points to a number of central problems that not yet been fully addressed, and need for a specific unity to the approach taken to solve such problems. Its core is how to build efficient governance mechanism so as to affect the knowledge movement such as sharing, retaining and creating knowledge, involving various subjects (knowledge management, organizational learning, strategy and human resource management, and so on). In turn, it is necessary to discuss the gaps in the extant literature that the open innovation has arisen for the knowledge governance requirement.

\subsection{Research gaps}

Lippman and Rumelt (2003) pointed out that people all strive for the residual value of "enterprise" or self-interest, actually this statement is misleading. Because the value distribution process is executed partially by enterprises, and partially controlled by stakeholders owning certain bargaining power. That is to say, "collectivism" often neglects the action rule of the micros mechanism while pursuing for the integration of individual human capital's knowledge and organization ability.

The occurrence of Open innovation essentially is due to knowledge dependence among different organizations instead of competence dependence. Competence dependence refers to the situation in which enterprises know what it wants to do, but need other enterprises' supplementary help. While knowledge dependence signals that enterprises don't know exactly how to accomplish certain tasks, and require specialists to provide skills and fill knowledge gap. So that we can see, knowledge dependence exposes organizations' risk in learning and innovation ability. The underlying argument seems to be that knowledge resources are particularly often the cause of competitive advantages and are the particularly major intension for firms choosing to cooperation. In turn, much attention has been paid to knowledge constructs such as capabilities placed on firm-level, successful firms control capabilities that result in more appropriable value-added than less successful firms. However, such explanatory stance is not satisfactory. There are two reasons for this.

First, it seems that something placed on the firm-level to something else is also placed on the firm-level, which is known as "methodological collectivism" (Hayek, 1952; Coleman, 1990), for it transcend the level of individual action and interaction. That is to say, we want to know how exactly the issue of individual knowledge is somehow integrated through organizational means into organization-level capability, and how this integration results in knowledge being utilized that competitive advantage becomes the result.

Second, the collectivist capability in strategy neglects individual subject. Obviously, open innovation can't be taken as the organizational processes that enable managers to carry out certain key tasks and orders, because such "open" environment appealing for equality and distributed authority. These rights allocation accompanying enforcement mechanisms constitute the distribution of authority, for an allocation of property rights is also an allocation of incentives (Barzel, 1997), including incentives to search for knowledge, share knowledge, and 
accumulate human capital. So we should make a sense of the links between knowledge and superior returns, not just because of their potentially beneficial effects on returns, but also some informal ties promote the knowledge allocation (Coff, 1999), while some undesirable behavior hinder the knowledge flow, such as the game behavior before the cooperative innovation, the insufficient knowledge investment and "free-rider" during the cooperative innovation, and the adverse ethic selection after the cooperative innovation, etc. Therefore, the allocation of incentives should stance on individual subject, by way of which collectivist capability will come true.

In current studies about open innovation, some focus on micro knowledge transfer activities, some focus on macro property design, the relationships among organizations, etc. few study concerns certain gaps existing in open innovation study from micro to macro. Here we suggest that knowledge Governance can start the new perspective of researching on open innovation.

\subsection{Cause of research gaps: Missing micro-foundations}

There are probably several reasons why the above research gaps exist. The following discusses the possible causes focus on the missing micro-foundations in knowledge movement within open innovation while ignoring of governance mechanisms as antecedents of knowledge process.

As shown, there are links between micro-micro (arrow 4) and macro-micro (arrow 1), micro-micro (arrow 2) and micro-macro (arrow 3) in fig.1. In Open Innovation, the aim is to explain a macro-level phenomenon, such as a firm-level outcome. But first we should lead the individual knowledge level and behavior towards organization demanded level (Hakansson and Johanson, 1993) (see Arrow 4). However, arrow 4 only be used in special situations though showing as a shorthand way of representing a fairly complex process. The reason exists for that there are no conceivable mechanisms that directly take us from the organization-level outcomes to the maximized value or unitized activity. So then we choose path 1, 2, 3 (Arrow 1,2,3) to integrate the scattered behaviors generated by innovative actors and maximize the value of knowledge by way of the more "micro" mechanisms. For presumably cross firm-level maximized value and united behavior, the individual or individual organization should utilize the knowledge in an optimal manner and do a key knowledge governance task. In Gulati and Gargiulo's view (1999), the social structure and performance of inter-organizational relations as a "macro" phenomenon emerges out of the "micro" decisions of organization seeking to gain access to share resources or knowledge and to minimize the uncertainty associated with cooperation. Hence the micro knowledge activities and macro emergence within the open innovation can be defined as "fixed mode which is the repeated, recognizable collective behavior reflected in the interactive action of organizational members in open innovation ".

\section{Insert Fig. 1}

\section{Antecedent Factors of Knowledge Governance within open innovation——Based on Grounded Theory}

The knowledge governance approach identifies, grapples with, and address problems that existing in the interactive organizations and knowledge processes within open innovation, problems for various causes are hard to solve within other knowledge-based approaches. So in the following we will explore the antecendent factors that influence the knowledge governance, the issue of what governance mechanisms are chosen to steer knowledge sharing, integration and creation associated with such impact factors. At present, rare theory study goes on Knowledge Governance within open innovation study, theoretical achievements of open innovation is little either. Lacking direct literature reference forces researchers to dump Literature Deductive Model, and dig corresponding laws from practical phenomenon. Accordingly, Grounded Theory would be a more reasonable choice to do relevant research.

\subsection{Material Collection}

(1) Literature Extraction Method. Drawing on 10 periodicals such as Management World, and works from domestic famous scholars, we extract some related statements about Knowledge Governance, open innovation, etc, which is used to be contrast statements during interviews.

(2) We once made the on-spot investigation through one industrial park in Ningbo and a large automobile manufacturing group in Shanghai, while doing the research funded by National Natural Science and the National Social. Thereafter we sorted records from the interviews and observation. This process altogether has experienced two stages.

Open interview stage, which was conducted in November 2009, focused on two problems: one is related to enterprise's basic circumstances (industry characteristics, scale), and technology innovation and product innovation status existing in enterprise. The other is the effect factors of knowledge activities within open innovation. In this process, two researchers participate at least. One was responsible for the interview, another worked on the record. On this basis, combining with extracted information from some literatures, we formed some organized statements through preliminary coding.

Semi-structured interview stage, went on in May 2010, which had three goals to achieve: make clear of the dimensionalities of Knowledge Governance within open innovation; Collect multiple evidence through in-depth interviews with department managers, technical and R\&D personnel from some typical enterprises so that 
provide more proofs to the research ideas; Explore the items not be found in former stage.

(3) When selecting respondents, we thought mainly from two aspects: first, respondents must come from large-scale enterprises owning innovation orientation, also they must have three years of $R \& D$ or innovative management experience (have once been or are participating or guide the relevant management work of R\&D or innovation, familiar with enterprise's development process, or have abundant similar working experience in daily work). Second, respondents must themselves have once been or are participating in the enterprise innovation and development, and to a certain extent familiar with R\&D or innovation process, etc. To sum up, our respondents mainly involves committee chairmen, department directors and technical staff in the industrial park mentioned above, etc.

Through a series of early selections, we eventually carry out interviews formally with 27 individual, and each interview is required to be hold for 90 minutes or more (so as to achieve depth interview). The source of respondents is widespread and typical, which meets requests of Grounded Theory about research objects. The descriptive statistics are shown in table 1.

\subsection{Data Analysis}

After collection of the initial data, we started to use Grounded Theory to organize and analyze data. This process is mainly divided into four steps: coding units' building, open coding, axial coding, and selective coding.

\subsubsection{Coding units' building}

Considering the purpose of this study, we made the relatively independent statement or segment with complete information in interview materials to be the smallest coding units, and preliminarily determined 158 analysis units closely related to Knowledge Management within the open innovation mode. The paragraphs below are extracted from interview materials, and the underlined sentences are the three analysis units among them.

(113) Our company belongs to motor industry, and the innovation process cannot move smoothly without manufacturers, users, governments, and even competitors' engaging. The company has specific department responsible for searching, obtaining, and transferring of new technology. The company purchases technology license to own the access to new-needed technology, which is used to establish core business and new technology platform.

(114) In the process of enterprise's open innovation activity, the enterprise's main external innovation sources are the user, supplier, distributor, university and research institution (including technology company), competitor, intellectual property institution, and the government, etc. Open innovation model is good and we always prefer outsourcing or cooperation, when we cannot finish a technology's R\&D alone or just because of no-extra energy on such technology.

(115) There remain some problems, such as the loss of key personnel, commercial secret leak, which cannot be completely avoided by contracting. Some enterprises are not willing to release core technology but covet in other enterprise's achievements. Sometimes this makes us consider repeatedly whether we really need cooperation. Even we decide to innovate through cooperation, we would like to choose the enterprises that we have a long time cooperated relationship, otherwise the possible opportunity cost is too high (laughing).

\subsubsection{Open coding}

Open coding procedure is to definite phenomena (conceptualization)first, then abstract categories, and name for the categories, finally dig the nature and properties dimensions for the categories, which aim is to identify the scene, define concept, discover categories, all of these are also called amass process.

\section{Insert table 2.}

Eventually we formed 59 concepts and 20 categories through the analysis just like above. We then do the reclassified integration of concepts due to the large number and overlap of concept. So give an analysis of category becomes subsequent focus.

\subsection{Axial Coding}

Axial coding could make each category derived from open coding together with the model (causality conditions - phenomenon - context - intermediary conditions - action - interactive strategy -- results), and use the conditions that lead to a certain event (in the main category), the dependent context (namely the category's specific dimension index), the adopted strategy and results by actors in the event. After model coding, this paper has came to four main categories - knowledge characteristics, knowledge activity parties, exogenous and endogenous situations of knowledge activities, and their own typical model, respectively refers to table 3,4, 5,6.

\section{Insert table 3 .}

Table 3 shows the knowledge characteristics' canonical model. In the model, knowledge tacit, knowledge diversity and contextual embeddedness, and the "public goods" nature are all the causality conditions of knowledge characteristics. Intermediary conditions are exogenous and endogenous situations of Knowledge 
Governance. Action strategy is the interactive value creation and incentive mechanism.

\section{Insert table 4.}

Table 4 shows the canonical model of parties of knowledge activity. Within it, cooperation motivation, enterprises' learning will and knowledge-protecting degree contribute to the causality conditions of the behaviors of parties of knowledge activity. Intermediary conditions are the ability of parties of knowledge activity and exogenous and endogenous situations of Knowledge Governance. Collective behavior integration and relational property mechanism are treated as the action strategy.

\section{Insert table 5.}

Table 5 illustrates the canonical model of Knowledge Governance exogenous situation. In which, knowledge distance and organizational distance constitute the most basic causality conditions. Knowledge's transfer degree and its accumulation maturity degree, institutionalized degree within the team make up the intermediary condition. The cognitive mechanism and trust mechanism acts as the action strategy.

\section{Insert table 6.}

Table 6 demonstrates the canonical model of Knowledge Governance endogenous situation. In the model, the most basic causality conditions include degrees of closeness of social relationship and management feature. When it is comes to the intermediary condition, they should be the interactive mechanism and staff game type. Action strategy involves in cognitive mechanism and trust mechanism.

\subsection{Story line and Core Category}

Among the four main categories abstracted from axial coding process, each category has its own canonical model and evidence chain, and each represents different characteristics and orientations as well. Whatever, it reflects a phenomenon of Knowledge Governance under open innovation though it cannot cover all contents. This phenomenon emerged with numerous influencing factors. So the research further sorted out the material with a line of "Story Chain".

"Story Chain" can be described as follows: an enterprise should take full use of the knowledge superiority from external innovation source to achieve innovation, when it decides to select the open innovation pattern. Thus firstly enterprise needs to search for enterprises or institutions with similar pattern by various means, and once these enterprises or institutions join in its innovation process, the most important thing is to share knowledge or to promote knowledge innovation as much as possible. However, degree of transferring knowledge varies according to different knowledge activity like cooperation motivation between enterprises and other innovation sources, closeness of social relationship, knowledge-protecting degree, and enterprises' learning attitude (action or interaction strategy). In addition, factors about knowledge itself such as knowledge tacit and the "public goods" nature also attribute to knowledge's transferring degree. So do knowledge diversity and contextual embeddedness (causality conditions). Then, we eventually concluded two main paths influencing knowledge's transferring degree within the open innovation: one is the interactive value creation process with knowledge property as its core. The other way is behavior unity process with knowledge activity parties as the main body. At the knowledge activity parties' level, variables associated with willingness and skills among Individuals or individual organization involved in the exchange relationship are of primary importance. At knowledge property level, variables associated with knowledge features and processes are likely to influence the way the open innovation is governed. Moreover, these two paths only launched by fully using the exogenous and endogenous context of knowledge activities (intermediary conditions). After a series of analysis and verification, it shows that the "Story Chain" could tell what is going on about the material collected, as fig. 2 shows.

\section{Antecedent factors and Interior Mechanism of Knowledge Governance within Open Innovation}

\subsection{Knowledge activity parties level antecedents of knowledge governance within open innovation}

Based on the above grounded theory analysis, knowledge activity parties show its significance and verifying features under open innovation. They take participate in the innovation team through self-identify, self-choice and self-evaluation of the innovative result, and their relations characterize by independent and equality but not attachment. Because of none specialized definition about the member's efforts by contracting and the member implement self-identify according their ability automatically, the authority centre within open innovation shows distributive attributes comparing to the single knowledge authority existing in bureaucracy. As Hayek (1952) said that, the expected knowledge flows requiring for the authority hold by knowledge rather than bureaucracy itself. In idea circumstance, knowledge sharing and product material cost lower enough, and it is accessible to knowledge resources freely or cheaply, so that a fully communication comes as a realization, instead of using mechanisms such as price or management. Based on such logic, activity parties in open innovation could make a clear distinction about what to do, what can do, who do what and what is the evaluation from others through such communication. Thereby, we can conclude that distributive authority and verifying activity parties enables the knowledge creation in open innovation ideally, but the potential dilemmas still remains. Such as the different motivation brought by verifying activity parties may lead to interest conflict and cross-communication level caused by distributive authority may increase the innovative complex, in turn some kind of undesirable behavior 
like "fee-rider" will be caused, which constitutes a new challenge to traditional governance mechanism. So we will turn to motivation involving invisible, internal, hypothetical construct and internal factors. Conscious or unconscious, people hold back their knowledge if the punishing is anticipated, one way or another, which can be defined as the set of psychological processes that initiate interactive related behavior (Latham and Pinder, 2005). Various kinds of knowledge hoarding behaviors may lead to rejection of knowledge sharing. Bossink (2002) once proposed that organizations choose or are forced to innovate in co-operation with other organizations, he argues that some firms first take part in innovation may only out of commercial interest. So it is especially important to focus on the individual or individual organization's willingness to collaborate as not all individuals could see the potential gains of collaboration at first sight.

Accordingly, the corresponding mechanisms to get rid of such dilemma should focus on the incentives for their willingness to cooperate with each other and achieve behavior unity to manage knowledge creation. The literature has created an impressive list of reasons for why individual knowledge activity comes into a unity. Some argues that the strategic behavior for open innovation is to recognize sourcing knowledge externally not only by minimization of transaction costs, but also the long competitive considerations (Tidd and Trewhella, 1997). Additionally, such strategy highlights more importance of maintaining fruitful relations to core partners via close relations. Many kinds of coordination mechanisms provide institutions for achieving the alignment of incentives among the partners. However, from the availability of these mechanisms, it is impossible to realize the harmony relationship between the activities of the partners. Meanwhile, a recurring criticism of the transaction cost literature applied to strategic cooperation is fails to acknowledge the role that non-transactional feature in alliance and cross-organization, even in open innovation.

Some literature gave a classification about the innovation alliance, that is "learning alliances" and "business alliance", the former is to learn and acquire from each other skills and knowledge (Lei and Slocum, 1992), while the latter is to maximize the utilization of complementary resources (Harrigan, 1985). A review of such literature shows strong similarity in open innovation. "Learning cooperation" is of significance to open innovation for achieving its knowledge innovation. However, as noted by Kanter (2002), open innovation can't be controlled by formal systems but require a dense web of interpersonal connections and internal infrastructures that enhance learning". This underlines the importance of continuous coordination incentives among parties, typically achieved via mutual exchange and embeddness of knowledge (Nielsen, 2005), through which the partners learn to adjust their activities to each other.

In such vein, Dyer and Singh (1998) has emphasized on investment in relation specific assets. Research has found that the bonds between key individuals are central mechanisms that initiate behavior unity formation (e.g., Larson, 1992). They also provide evidence for the importance employing effective governance mechanisms in their quest for gaining relational rents. One of the specific factors that are leading to relational rents requires for knowledge sharing routines, these routines are institutionalized cross-organization processes that are purposefully designed to facilitate knowledge exchange between activity parties in open innovation. The development and employment of these routines constitute a firm's dynamic capabilities that is the ability to "integrate, build and reconfigure internal and external competencies" in rapidly changing environments (Teece et al., 1997).

\subsection{Knowledge property level antecedent of knowledge governance within open innovation}

Discussions in existing organizational literatures pay more attention to levels in micro-foundations in particular (for a discussion see Felin and Foss, 2005). However, the vast majority of these studies take organization as the unit of analysis, thereby lacking attention to individual level knowledge sharing process based on knowledge property. Such knowledge property constitutes the basic obstacles among the knowledge sharing, for its complexity, tacitness and contextual-embedness. We concur with Leung and White who state that, "so much is at stake in the open innovation, as reflected by the voluminous firm-level research on this topic, but we know so little about the relevant people issues and their knowledge brought that make or break open innovation"(Leung and White,2006). Some researches argue that the transfer of tacit knowledge cannot be controlled by contracting, and activity parties cannot be sanctioned for holding back tacit knowledge. While explicit knowledge can easily be communicated and transferred among individuals, space and time (Grant, 1996, p. 111).

More importantly, there's appearing complex situation and new content in knowledge property within open innovation. First, knowledge also shows distributive feature with the form embedding in activity parties. The cooperation parties strive for more innovative rent they even wish to pay more, or assume certain loss in the communication cost and the potential cost caused by knowledge spillover (Dietrich, 1994). So that knowledge sharing and new knowledge co-creation take a priority, as thus, in one side the enterprise wants to go ahead in technology while pursue for product efficiency in the other side, and their knowledge borders will be expanded and some fuzziness will lead. In addition, with the communication level increase, the knowledge borders within open innovation becomes more complex and gradually severs as platform for the communication and interaction across-organizations dynamically, rather than the static role in organization. Literature research shows that it will cause creative abrasion for the time lag in knowledge interactive process (Leonard- Barton, 1995). So some researches dispute the paradox that the knowledge innovation could serves as the source of open innovation in 
one side, but hinders sometimes oppositely (Carlile, 2002).Considering the objective of knowledge governance is to optimize of the knowledge movement within open innovation. In times of knowledge economy, if enterprise wants to stand out from the market competition, they should accelerate the rate of knowledge creation.

As a matter of fact, the ability or motivation to share knowledge is impeded by two conditions: humans are cognitively constrained in the speed they learn and are prone to self-interest. The wide distribution of knowledge in blended with self-interest leads to two knowledge-related exchange hazards: knowledge appropriation and strategic knowledge accumulation. So the interactive value creation is a preferred way of acquiring and creating knowledge in open innovation (Ring and Van de Ven, 1994; Powell et al., 1996).

Interactive value creation refers to a suit of documented-knowledge operation procedures. Sometimes it is presented in the explicit coding way, sometimes in the implicit coding. The collision and dialogue between knowledge is a key issue in the interactive process. In the way of open innovation towards innovative ability, we should extremely absorb, master, integrate and utilize various kind of knowledge. As for suppliers and manufacturers, there are potential need for knowledge expanding in their empty knowledge field, so knowledge interaction and communication is no longer a one-way output within the open innovation, neither an economic market exchange, but a kind of social exchange and reciprocal interaction. These kinds of responses based on mutual benefit, trust and mutual control mainly function for the full sharing of knowledge, and in turn serve for interactive innovation process of knowledge. Given that tacitness increases the costs of making explicit agreements, delegation of the right to initiate, carry out, etc. So our next example concerns the use of delegation in open innovation context of sharing knowledge. Such activity with third party seems to be an efficient alternative to ensure specific knowledge sharing.

\subsection{Interior working mechanism of knowledge governance within open innovation}

In sum, knowledge governance implementing involves the above two activity, behavior unity (leaded by knowledge activity parties) and interactive value creation process (leaded by knowledge property), we call it "dual-type" working mechanism. It is the interaction between both levels that exposes the true complexity of knowledge sharing and governance in open innovation. Only by studying the combined effects of both level antecedents of knowledge governance and resolving the potential problem existing in them can we arrive at an understanding of how to facilitate more effective knowledge governance performance and in turn successfully open innovation. So firstly we should reach the target in micro level by executing two routes, and in the process of micro behaviors towards macro emergence, we take a series of action strategies like mechanism I and II so as to influence macro representation of open innovation, such as cognitive change, behavior change and discourse power change, etc.

\section{Insert Fig.2.}

\section{Discussions and Conclusions}

In this paper, we have argued that knowledge governance is formed by the interplay between knowledge property with distributive feature and verifying knowledge activity parties. As an exploratory and basic research, we reach the preliminary conclusion just as follows:

\subsection{Antecedent factors of Knowledge Governance within open innovation}

According to Grounded Theory analysis, four dimensions (knowledge property of external innovation source, knowledge activity parties, exogenous and endogenous context of knowledge) affect Knowledge Governance performance, and the long-term repeatable, dynamic interaction among these four factors push the whole process of open innovation forward. We have shown that knowledge governance is positively affected by a number of factors some are knowledge itself and some are knowledge activity parties in nature. It is the interaction between both levels that exposes the true complexity of knowledge governance within open innovation. The proposed framework may guide future research in the pursuit of more complete understanding roles of knowledge property-level and knowledge parties-level antecedents of knowledge governance, especially worth noting that, distributive features and verifying property add new content in open innovation. It may provide reference for evaluating the potential tradeoff or substitution effects of governance mechanisms. Our research argues that, only if achieving fully interaction and matching of various knowledge attributes and links can we realize the sufficient governance of open innovation.

\subsection{Some problems in Local enterprises carrying out open innovation still remains}

In this grounded-theory research process, we continually feel that more difficulties rooted in local enterprises. Though it is still a general fact since open innovation could provide unlimited vision and help promote long-term performance. Open innovation is yet mistakenly implemented. These domestic enterprises are so persistently interested in pursuing short-term interests that they can't maintain relatively interests in originality and their high dependence on external innovation sources is mainly up to weak dependence on weak resource, like outsourcing some businesses with no advantages. This disadvantaged dependency makes enterprises impossibly neither play role in innovation party, nor can realize effective "innovation during the cooperation". If we define "open innovation" as any form of cooperation with a third party adopted a long run view, possibly more domestic 
companies would be ruled out. In addition, during the opening practice, we see that knowledge transfer only occurs with personal contact occasionally, far from achieving the expecting result that innovators fully join (the number of "open innovation" partners is limited). So the quality and gap of knowledge transfer are still inevitable. Besides, local enterprises even pay no deserved attention to successful experience in open innovation practice, and have not much discussion on it. Therefore it is still not much scientific study of relevant fields here. "Dual-type working mechanism of Knowledge Governance" concluded in this paper is a preliminary exploring and summary about the innovation practice.

In sum, the key to open innovation is carrying out the systematic governance based on knowledge's micro nature. In this paper, the explorative study we had made is also a kind of opening discussion. Interactive knowledge creation and behavior unity must be supported by the implementation of knowledge governance mechanisms towards the structuring of knowledge flows automatically within open innovation, and ultimately influence the macro emergence. Therefore, these governance mechanisms are undoubtedly worthy of our further exploration.

Regardless of whether the motive for entering into a collaborative relationship is cost or not, however, verifying parties and distributive authority they hold create various strategic issues to be handled will make a difference to open innovation, such as the dilemma of how much knowledge to disclose in the project (Carter, 1989), the existence of various knowledge related asymmetries between partners, and so on. Yet, knowledge governance of interactive value creation and achieving behavior unity is a less fertile approach to mitigate these challenges. It is therefore important to ensure that the innovators involved in the actual knowledge sharing activity and knowledge creation through distributive authority. Furthermore, it is necessary to perceive the knowledge sharing requirement and cooperation incentives as on going through the entire innovative relationship, rather than being seen as an end product. As a result, knowledge governance mechanisms are highly important during all phases of collaborative relationships, and may serve as complements to more formal control systems.

At the present stage development, what is arguably most needed, however, is empirical work that can assist in identifying knowledge-based hazards, ascertain how organizations deal with such hazards by deploying governance mechanisms within open innovation, and find out how these mechanisms are characteristically combined, all will be our future research work.

\section{References}

Bossink, B.A.G. (2002). The development of co-innovation strategies: stages and interaction patterns in interfirm innovation. $R \& D$ Management, 32(4), 311-320.

Caloghirou Y, Kasteli I, \& Tsakanikas A. (2004). Internal capability and external knowledge sources: complements or substitutes for innovation performance?. Technovation, 24(1):29-39.

Glaser, Barney and Strauss, Anselm L. (1967). The discovery of grounded theory: Strategies for Qualitative Research. Aldine de Gruyter.

Grandori, A. (1997). Governance structures, Coordination Mechanisms and Cognitive Models. Journal of anagement and Governance, 1 (1): 29-47.

Grant, Robert M. (1996). Towards a Knowledge-based Theory of the Firm. Strategic Management Journal, 17: 109-122.

Kogut, Bruce and Udo Zander. (1992). Knowledge of the Firm, Combinative Capabilities and the Replication of Technology. Organization Science, 3: 383-397.

Lippman, Steven A., and Richard P. Rumelt. (2003). The Payments Perspective. Strategic Management Journal, 24: 03-927.

Luo Min and He Chang-jian. (2006). Interorganizational Relationship: Interface Rules and Governance Mechanism. China Industrial Economy.

Organ D W, Ryan K. (1995). A meta-analytic review of attitudinal and dispositional predictors of organizational citizenship behavior. Personnel Psychology, 48(4): p. 775.

Prahalad, C. K., \& Krishnan, M. S. (2008). The New Age of Innovation: Driving Co-created Value through Global Networks. New York: McGraw-Hill.

Ring, P.S., and A.H. Van de Ven. (1994). Developmental processes of cooperative inter-organizational relationships. Academy of Management Review, 19: 90-118.

Shan R.H., and Swaminathan V. (2008). Factors Influencing Partner Selection in Strategic Alliances The Moderating Role of Alliance Context. Strategic Management Journal, 29-50.

Spender, J.C. (1996). Making Knowledge the Basis of a Dynamic Theory of the Firm. Strategic Management Journal, 17 (Winter special issue): 45-62.

Spender, J.C. (2005). Review Article: An Essay of the State of Knowledge Management. Prometheus, 23: 101-116.

Tidd, J., and M. Trewhella. (1997). Organizational and technological antecedents for knowledge acquisitionand 
learning. $R \& D$ Management, 27(4): 359-375.

West, J. (2003). How open is open enough? Melding proprietary and open source platform strategies. Research Policy, 32: 1259-1285.

Zurcher LA. (1982). The staging of emotion: A dramaturgical analysis. Symbolic Interaction, 5: 1 22

Table 1. Distribution of Sample Data

\begin{tabular}{|c|c|c|c|}
\hline Item & Sort & Number of Samples & Percentage \\
\hline \multirow{3}{*}{ Sample } & Effective & 27 & $100 \%$ \\
\cline { 2 - 4 } & Ineffective & 0 & $0.0 \%$ \\
\hline \multirow{3}{*}{ Company } & Large-scale enterprise & 14 & $51.9 \%$ \\
\cline { 2 - 4 } & Research institutions & 11 & $40.7 \%$ \\
\cline { 2 - 4 } & Liberal professions & 2 & $7.4 \%$ \\
\hline \multirow{3}{*}{ Position } & Senior management & 1 & $3.7 \%$ \\
\cline { 2 - 4 } & Middle management & 7 & $26.0 \%$ \\
\cline { 2 - 4 } & Junior management & 19 & $70.3 \%$ \\
\hline \multirow{3}{*}{ Education } & Doctor & 15 & $55.6 \%$ \\
\cline { 2 - 4 } & Master & 5 & $18.5 \%$ \\
\cline { 2 - 4 } & Undergraduate & 6 & $22.2 \%$ \\
\cline { 2 - 4 } & Other & 1 & $3.7 \%$ \\
\hline
\end{tabular}

Table 2. Materials from Open Coding

\begin{tabular}{|c|c|c|c|}
\hline \multirow{2}{*}{$\begin{array}{l}\text { Interview materials after } \\
\text { transcription }\end{array}$} & \multicolumn{3}{|c|}{ Open coding } \\
\hline & Primary concept & Formal Concept & Categorization \\
\hline $\begin{array}{l}\text { I often participate in the enterprise } R \& D \\
\text { project because I would like to pursue new } \\
\text { things... } \\
\text { I am very interested in scientific research, } \\
\text { and always prefer to use my own } \\
\text { knowledge... }\end{array}$ & $\begin{array}{l}\text { The cooperative innovation } \\
\text { consciousness of innovation } \\
\text { sources, ideas about the } \\
\text { cooperative innovation, motivation } \\
\text { of carrying out cooperative } \\
\text { innovation, the willing of } \\
\text { innovation sources to participate in } \\
\text { enterprise innovation... }\end{array}$ & $\begin{array}{l}\mathrm{A}_{1}: \text { Cooperation } \\
\text { consciousness } \\
\mathrm{A}_{2}: \text { Cooperation } \\
\text { motive }\end{array}$ & $\begin{array}{l}\text { AA: } \\
\text { Cooperation } \\
\text { motive }\end{array}$ \\
\hline $\begin{array}{l}\text { Our enterprise has been advocating } \\
\text { competition and encouraging innovation. } \\
\text { This kind of enterprise culture will help } \\
\text { carry out research and innovation } \\
\text { activities... } \\
\begin{array}{l}\text { Support employees' innovation } \\
\text { behaviors... }\end{array}\end{array}$ & $\begin{array}{l}\begin{array}{l}\text { Enterprise culture } \\
\text { competition, }\end{array} \\
\text { advocates } \\
\text { innovation activities, tolerates } \\
\text { innovation failure. Therefore } \\
\text { minimize innovation pressure; } \\
\text { Give innovation support; Cultivate } \\
\text { innovative consciousness... }\end{array}$ & $\begin{array}{l}\mathrm{A}_{3} \text { : External } \\
\text { innovation source' } \\
\text { depth } \\
\mathrm{A}_{4} \text { : External } \\
\text { innovation source' } \\
\text { scope } \\
\mathrm{A}_{5} \text { : External } \\
\text { innovation source' } \\
\text { applied range }\end{array}$ & $\begin{array}{l}\mathrm{AA}_{2} \text { : } \\
\text { Knowledge } \\
\text { ability }\end{array}$ \\
\hline $\begin{array}{l}\text { I think I'm in the business areas which my } \\
\text { enterprise is exploring, and my knowledge } \\
\text { will help its R\&D and innovation... } \\
\text { There are still a lot of problems between } \\
\text { us. The solution of these problems will } \\
\text { promote the innovation activities... }\end{array}$ & $\begin{array}{l}\text { Complementary } \\
\text { between firms advantages } \\
\text { innovation sources; Restriction by } \\
\text { and collaboration with each } \\
\text { other... }\end{array}$ & $\begin{array}{l}\mathrm{A}_{6}: \text { Interests } \\
\text { distribution } \\
\mathrm{A}_{7}: \text { Bonus payments } \\
\mathrm{A}_{8}: \text { Property rights }\end{array}$ & $\begin{array}{l}\mathrm{AA}_{3}: \\
\text { Knowledge } \\
\text { protection } \\
\text { degree of the } \\
\text { provider }\end{array}$ \\
\hline $\begin{array}{l}\text { When we participate in the cooperation, } \\
\text { we are all willing to study hard and try my } \\
\text { best to master the other's technical } \\
\text { knowledge, our company arranged many } \\
\text { people specializing in this technology } \\
\text { transfer activity. Our company has } \\
\text { provided all the facilities for transferring } \\
\text { the technology... }\end{array}$ & $\begin{array}{l}\text { Willing to study hard and try my } \\
\text { best to master the other's technical } \\
\text { knowledge, professional personnel } \\
\text { engaged in technology transfer } \\
\text { activity, have facilities used to } \\
\text { transfer technology... }\end{array}$ & $\begin{array}{l}\mathrm{A}_{34}: \text { Willing to make } \\
\text { efforts } \\
\mathrm{A}_{35}: \text { Appropriate } \\
\text { facilities...... }\end{array}$ & $\mathrm{AA}_{4}$ : Study will \\
\hline
\end{tabular}


Table 3. AA9 Canonical Model of Knowledge Property

\begin{tabular}{|c|c|c|}
\hline Causality conditions & \multicolumn{2}{|c|}{ Phenomenon } \\
\hline $\begin{array}{l}\text { Knowledge tacit } \mathrm{AA}_{7} \\
\text { Diversity and context embeddedness } \mathrm{AA}_{6} \\
\text { "Public goods" nature } \mathrm{AA}_{8}\end{array}$ & \multicolumn{2}{|c|}{ Knowledge PropertyAA 9} \\
\hline Nature of causality conditions & \multicolumn{2}{|c|}{ Feature-oriented } \\
\hline $\begin{array}{l}\text { Different business areas } \\
\text { Different knowledge characteristics }\end{array}$ & $\begin{array}{l}\text { Quality control } \\
\text { Innovation capitalists } \\
\text { Cooperative innovation experience }\end{array}$ & $\begin{array}{l}\text { High evaluation standard } \\
\text { Industry experts ability } \\
\text { Rich experience } \\
\end{array}$ \\
\hline
\end{tabular}

During the innovation process of innovation sources mainly including lead users, average consumer, external scientists and engineers, knowledge activities will be influenced by knowledge itself and knowledge characteristics under the open environment. We can unfold an interactive innovation with innovative enterprises in different strategies based on interactive value creation, trust mechanism and so on.

\section{Intermediary conditions}

Knowledge Governance exogenous context $\mathrm{AA}_{14}$

Knowledge Governance endogenous context $\mathrm{AA}_{20}$ Action/ interactive strategy

From the Micro view, knowledge characteristics of external innovation source have remarkable effect on Knowledge

Governance performance, and the individual organization discourse power from the macro view.

Table 4. AA5 Canonical Model of Parties of Knowledge Activity

\begin{tabular}{|c|c|c|}
\hline Causality Conditions & & enomenon \\
\hline $\begin{array}{l}\text { Cooperation motive AA1 } \\
\text { Study will AA4 } \\
\text { Knowledge protection degree AA3 }\end{array}$ & \multicolumn{2}{|c|}{ Parties of knowledge activity $\mathrm{AA}_{5}$} \\
\hline Nature of causality conditions & \multicolumn{2}{|c|}{ Feature-oriented } \\
\hline $\begin{array}{l}\text { Willingness to cooperate determines the } \\
\text { sharing of knowledge } \\
\text { self-identify, self-choice and self-evaluation }\end{array}$ & $\begin{array}{l}\text { Innovation source search } \\
\text { Knowledge ability } \\
\text { Innovation cost }\end{array}$ & $\begin{array}{l}\text { Search breadth and depth } \\
\text { High demand } \\
\text { Appropriate cost control }\end{array}$ \\
\hline \multicolumn{3}{|c|}{ Action context } \\
\hline \multicolumn{3}{|c|}{$\begin{array}{l}\text { Since the enterprises which improve their ability by obtaining external innovation knowledge, will be affected by the } \\
\text { cooperation motivation between enterprises and other innovation sources, it encourages knowledge-sharing behavior of } \\
\text { knowledge activity parties in different ways such as institutionalization and accumulation of some specific knowledge, } \\
\text { the corresponding initiative (contained in endogenous and exogenous contexts), combining with collective behavior } \\
\text { integration, relationship mechanism, etc. }\end{array}$} \\
\hline \multicolumn{2}{|c|}{ Intermediary conditions } & Action/ interactive strategy \\
\hline \multicolumn{2}{|l|}{$\begin{array}{l}\text { Knowledge Governance exogenous context AA14 } \\
\text { Knowledge Governance endogenous context AA20 } \\
\text { Knowledge ability AA2 }\end{array}$} & $\begin{array}{l}\text { Collective behavior integration, } \\
\text { relational property mechanism }\end{array}$ \\
\hline \multicolumn{3}{|c|}{ Results } \\
\hline \multicolumn{3}{|c|}{$\begin{array}{l}\text { Parties of knowledge activity have an impact on Knowledge Governance performance at a micro level, and influence } \\
\text { organizational opportunism behaviors at a macro level. }\end{array}$} \\
\hline
\end{tabular}

Table 5. AA14 Canonical Model of Knowledge Governance Exogenous Context

\begin{tabular}{|c|c|}
\hline Causality Conditions & Phenomenon \\
\hline $\begin{array}{l}\text { Knowledge distance } \mathrm{AA}_{11} \\
\text { Organizational distance } \mathrm{AA}_{10}\end{array}$ & Knowledge Governance exogenous context $\mathrm{AA}_{14}$ \\
\hline Nature of causality conditions & Feature-oriented \\
\hline $\begin{array}{l}\text { Objective conditions and state between enterprises and other } \\
\text { innovation sources }\end{array}$ & $\begin{array}{l}\text { Induce differences and } \\
\text { complexity }\end{array}$ \\
\hline \multicolumn{2}{|c|}{$\begin{array}{ll} & \text { Action context }\end{array}$} \\
\hline \multicolumn{2}{|c|}{$\begin{array}{l}\text { The enterprises taking innovation as the orientation and external innovation sources play different roles in open } \\
\text { innovation, both of which are influenced by knowledge distance, organizational distance, etc. in the process of } \\
\text { knowledge transfer. Variable differences between them can be accommodated based on appropriate information means, } \\
\text { monitoring and feedback mechanism, cognitive mechanism. }\end{array}$} \\
\hline Intermediary conditions & Action/ interactive strategy \\
\hline $\begin{array}{l}\text { Knowledge transfer degree within the team } \mathrm{AA}_{15} \\
\text { Knowledge accumulation maturity degree } \mathrm{AA}_{16} \\
\text { Knowledge-institutionalized degree } \mathrm{AA}_{17}\end{array}$ & Cognitive mechanism, trust mechanism \\
\hline \multicolumn{2}{|c|}{ Results } \\
\hline Governance & 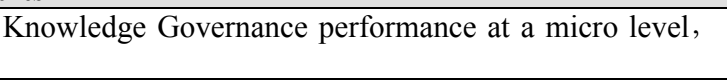 \\
\hline
\end{tabular}


Table 6. AA20 Canonical Model of Knowledge Governance Endogenous Context

\begin{tabular}{|c|c|c|}
\hline Causality Conditions & & Phenomenon \\
\hline $\begin{array}{c}\text { Degree of closeness of social relationship } \mathrm{AA}_{12} \\
\text { Management feature } \mathrm{AA}_{18}\end{array}$ & \multicolumn{2}{|c|}{ Knowledge Governance endogenous context $\mathrm{AA}_{20}$} \\
\hline Nature of causality conditions & \multicolumn{2}{|r|}{ Feature-oriented } \\
\hline Enterprises' Endogenous efforts & Increase subjective degree & Induce differences and complexity \\
\hline \multicolumn{3}{|c|}{ Action context } \\
\hline \multicolumn{3}{|c|}{$\begin{array}{l}\text { The enterprises taking innovation as the orientation and external innovation sources play different roles in open innovation, both of } \\
\text { which are influenced by the degree of closeness of social relationship, the interactive mechanism, etc. in the process of knowledge } \\
\text { transfer. Develop this relationship could base on appropriate coordination, benefit sharing, cognitive mechanism. }\end{array}$} \\
\hline Intermediary conditions & \multicolumn{2}{|c|}{ Action/ interactive strategy } \\
\hline $\begin{array}{l}\text { Interactive mechanism } \mathrm{AA}_{13} \\
\text { Staff game type } \mathrm{AA}_{19}\end{array}$ & \multicolumn{2}{|c|}{ Cognitive mechanism, trust mechanism } \\
\hline \multicolumn{3}{|c|}{ Results } \\
\hline \multicolumn{3}{|c|}{$\begin{array}{l}\text { Knowledge Governance endogenous context has an impact on Knowledge Governance performance at a micro level, and influences } \\
\text { organizational cognitive failure at a macro level. }\end{array}$} \\
\hline
\end{tabular}

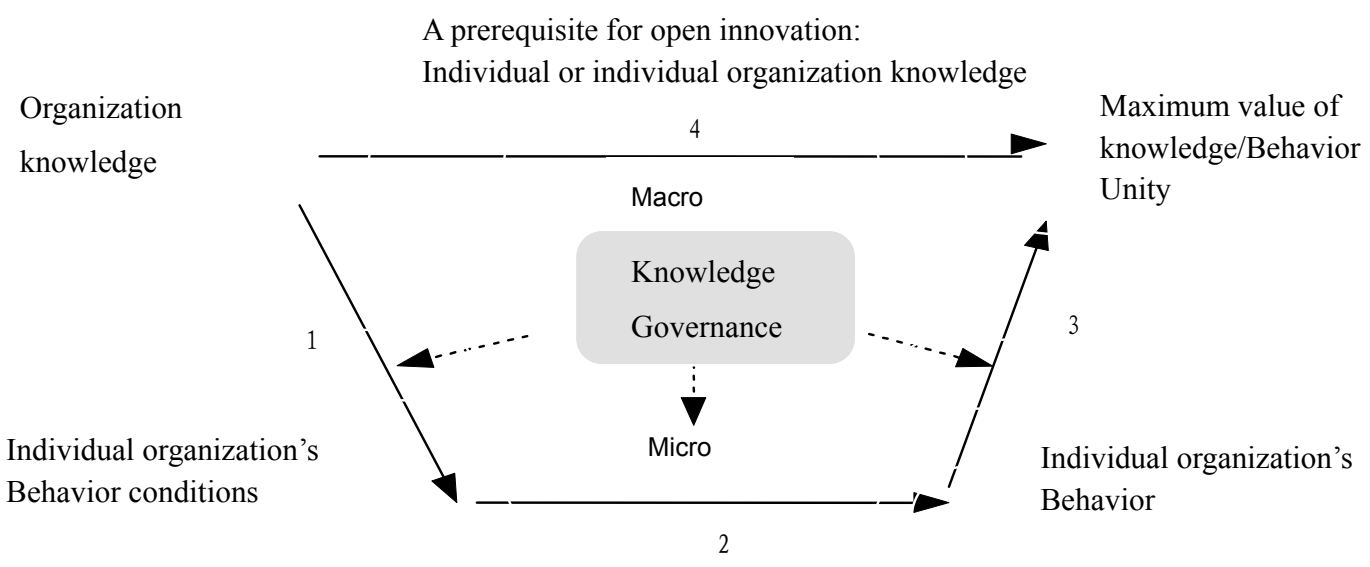

Figure 1. Significance of Knowledge Governance for open innovation (Drew up by author)

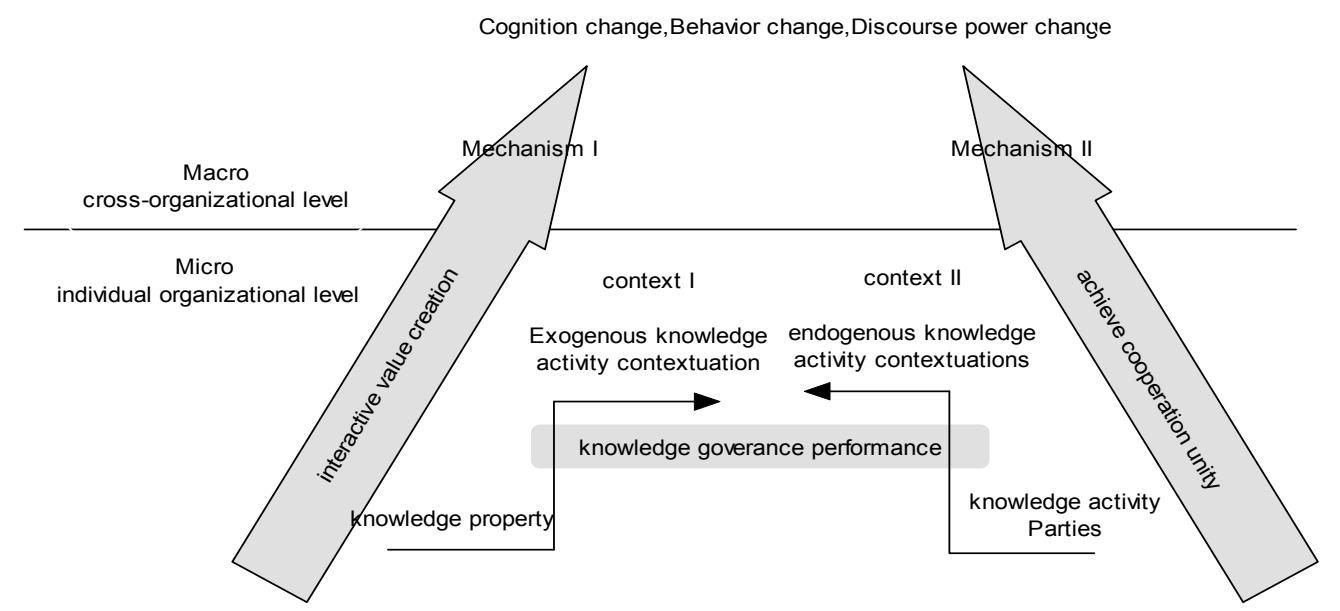

Figure 2. Internal Function Mechanism of Knowledge Governance within Open Innovation Mode 